\title{
Potential Geographical Distribution and Ecological Suitability of Lemon in Sichuan Based on MaxEnt
}

\author{
Yanyan Liu ${ }^{1,4}$, Huan Liu', Xin Xu' ${ }^{1,2}$, Yujia Zou ${ }^{3}$, Yufang Zhang ${ }^{3,4}$, Rulin Wang ${ }^{1,4,5 *}$ \\ ${ }^{1}$ School of Atmospheric Sciences and Plateau Atmosphere and Environment Key Laboratory of Sichuan Province, \\ Chengdu University of Information Technology, Chengdu 610225, Sichuan, China \\ ${ }^{2}$ Institute of Tibetan Plateau Research, Chinese Academy of Sciences, Beijing 10010, China \\ ${ }^{3}$ Sichuan Province Agro-meteorological Center, Chengdu, 610072, Sichuan, China \\ ${ }^{4}$ Water-Saving Agriculture in Southern Hill Area Key Laboratory of Sichuan Province, Chengdu 610066, Sichuan, China \\ ${ }^{5}$ Sichuan Provincial Rural Economic Information Center, Chengdu 610072, Sichuan, China
}

Received: 10 June 2021

Accepted: 15 October 2021

\begin{abstract}
In this study, the distribution information of lemon planting and the surface observation data during 1971-2017 from meteorological stations in Sichuan Province are adopted to reasonably plan the layout of lemon planting in Sichuan Province. Considering the elements of climate, soil and terrain affecting the planting distribution of lemon, 16 ecological factors are selected for the analysis and regionalization of the ecological suitability of lemon planting in Sichuan Province. Specifically, the maximum entropy model is used to establish the model for the relationship between the planting distribution of lemon and one of its potential influencing factors related to the climate. On this basis, dominant climatic factors affecting the planting distribution of lemon are investigated, and the distribution for corresponding suitability grades of these climatic factors are also revealed. The receiver operating characteristic curve is used to verify the simulation accuracy. The Jackknife method and correlation analysis are used to screen dominant climatic factors and analyze their relationship with the existence probability. Based on the ArcGIS platform, the spatial distributions for the regionalization indexes of soil and terrain are analyzed for the soil and terrain suitability regionalization of lemon planting in Sichuan Province. Furthermore, by using the ecological suitability analysis method and considering the weights of various indexes, the ecological suitability regionalization of lemon planting in Sichuan Province is obtained. The results show that the highly suitable regions for lemon planting with an area of $29,000 \mathrm{~km}^{2}$ are mainly concentrated in Guang'an City, Nanchong City, Suining City, Ziyang City, Neijiang City and Zigong City, and some regions scattered in the Sichuan Basin as well. In addition, there are also some
\end{abstract}

\footnotetext{
*e-mail: wrl_1986_1@163.com
} 
highly suitable planting spots for lemon in Panzhihua City. The moderately suitable region covers an area of $39,000 \mathrm{~km}^{2}$, and most of which are distributed in the mountainous areas in eastern part of the basin, such as the Guang'an City, Dazhou City, Suining City and Zigong City. The slightly suitable region with an area of $67,000 \mathrm{~km}^{2}$ is mainly concentrated in the central Sichuan Province, surrounding the highly and moderately suitable regions. The unsuitable region covers an area of $53,000 \mathrm{~km}^{2}$, which is mainly concentrated in plateau and mountainous regions of the western and northern Sichuan Province.

Keywords: lemon, ecological suitability, regionalization, maximum entropy model, ArcGIS

\section{Introduction}

Lemon is a tropical plant which belongs to the small evergreen tree in the genus Citrus of the family Rutaceae. Regions with warm winters and cool summers where the temperature changes smoothly are suitable for the planting of lemon. Lemon is rich in vitamin $\mathrm{C}$, sugar, calcium, vitamin B1, vitamin B2, citric acid, malic acid, high potassium and low sodium elements, which is very beneficial to the human body. The first country in the world to grow lemons is India. While currently the producing areas are mainly located in the United States and France. The yield of lemons planted in Anyue County, Ziyang City of Sichuan Province accounts for more than four-fifths of the total in China. Anyue lemon is not only popular in China, but also has been increasingly recognized in foreign countries. In recent years, the export volume of lemon has kept increasing year by year. Analyzing and evaluating the ecological suitability of lemon in the target area can not only avoid the problems of single variety and poor resistance to diseases and pests, but also help to optimize the industrial structure of lemon and improve the level of planting management [1-3].

In previous studies, the suitability regionalization of crop planting usually focuses on the single relationship between crops and climatic factors [4], but ignoring the impacts of other ecological factors such as soil and terrain in the study area [5]. Besides, there are few studies on ecological suitability evaluation considering multi-factors [6]. With the continuous improvement in the preciseness and accuracy of climatic, soil and terrain data, the application of the ArcGIS in crop planting regionalization has become one of the main methods for regionalization analysis $[7,8]$. For example, the influences of climatic and soil factors have been comprehensively analyzed in the regionalization for ecological suitability of Chinese medicinal materials $[1,9]$. By analyzing the distribution of target species in target areas with specific data, the species distribution model explores the influence of external factors on the distribution of species, which provides a method for regionalization analysis [10-13]. At present, the maximum entropy (MaxEnt) model has been widely used in crop planting regionalization, which is based on the maximum entropy principle
[14]. Based on the distribution information of crop planting and environmental factors, MaxEnt calculates the distribution probability of crops when the entropy reaches its maximum. Thus, the suitability of crop planting in the study area can be obtained. A large number of studies have proved that the MaxEnt is more applicable to suitability analysis for crop planting [15-18], which is of practical significance.

At present, in-depth researches on lemon planting and variety breeding have been conducted in China and abroad $[19,20]$, but few on the regionalization distribution of comprehensive ecological suitability. In this case, based on the ArcGIS software, the MaxEnt model is used to analyze the ecological suitability of lemon planting. By comprehensively considering multifactors (meteorological factors, terrain factors and soil factors) affecting the lemon planting, the regionalization for lemon ecological suitability is carried out, aiming to provide theoretical references for the reasonable planning of lemon planting distribution in Sichuan Province.

\section{Materials and Methods}

\section{Study Area}

Sichuan Province is located in the southwest hinterland of the upper reaches of the Yangtze River in China, with coordinates of $97^{\circ} 21^{\prime} \sim 108^{\circ} 33^{\prime} \mathrm{E}$ and $26^{\circ} 03^{\prime} \sim 34^{\circ} 19^{\prime} \mathrm{N}$, covering an area of $48.6 \times 104 \mathrm{~km}^{2}$. Sichuan is a typical monsoon climate with simultaneous rain and heat. Affected by geographical latitude and landform, the climate difference between the east and the west is significant [21]. Sichuan is the main lemon producing area in China and one of the five largest lemon producing areas in the world. The planting area of lemon in Sichuan exceeds $10 \times 10^{4} \mathrm{~km}^{2}$, accounting for $80 \%$ of the national planting area. In view of the importance of lemon in Sichuan's agricultural industry, we selected this area as the research object.

\section{Distribution Data of Lemon and Its Processing Method}

The MaxEnt model requires species distribution data and environmental data for simulation, where 
the species distribution data refers to the position information (longitude and latitude) of the presence localities. In this study, the lemon distribution data are obtained from the following three aspects. The first is field investigation, and most of the sampling points in Sichuan are obtained from field investigation with the position information (latitude and longitude) recorded by the global positioning system. The second is querying the species distribution database. The databases to be queried in this study include the Centre for Agriculture and Bioscience International (CABI, http://www.cabi.org/) database, the Global Biodiversity Information Facility (GBIF, http://www. gbif.org/) and the Specimen Resources Sharing Platform for Education (http://mnh.scu.edu.cn/). The third is retrieving lemon-related journal articles published at home and abroad. Through the above methods, 186 distribution data were obtained. The spatial analysis function of ArcGIS is used to calculate the distance between the distribution points and the center of the censored grid. Since the spatial resolution for environmental variables is about $1 \mathrm{~km}$, the buffer radius is set to $0.5 \mathrm{~km}$ to ensure that each censored grid contained only one distribution point closest to the center to reduce the effect of spatial autocorrelation [22, 23]. Finally, 132 distribution points are obtained, with the longitude and latitude determined by the Google earth (Fig. 1). By referring to the operation manual for the MaxEnt software, the latitude and longitude coordinates are entered into a Microsoft Excel, and saved in the format of '.csv'. Fields in the file include the species name, latitude and longitude [17, 24].

\section{Data Sources and Processing for Environmental Variables}

The meteorological data are obtained from the Sichuan Meteorological Observation Data Center. The ground-based observations of meteorological elements from weather stations in Sichuan Province and its surroundings during 1971-2017, including daily mean temperature, maximum temperature, minimum temperature, precipitation, sunshine duration, etc., are selected for the statistics and calculation of climatic indexes.

The soil data is obtained from the Soil Sub-center of the National Earth System Science Data Center in the National Science and Technology Resource Sharing Service Platform. By rasterizing the classified soil types, regions with different soil types and different soil $\mathrm{pH}$ values are screened out.

The terrain data is derived from the 1:250000 digital elevation model (DEM), which is provided by the National Geomatics Center of China, and the ArcGIS software is used to extract the information of slope and slope aspect.

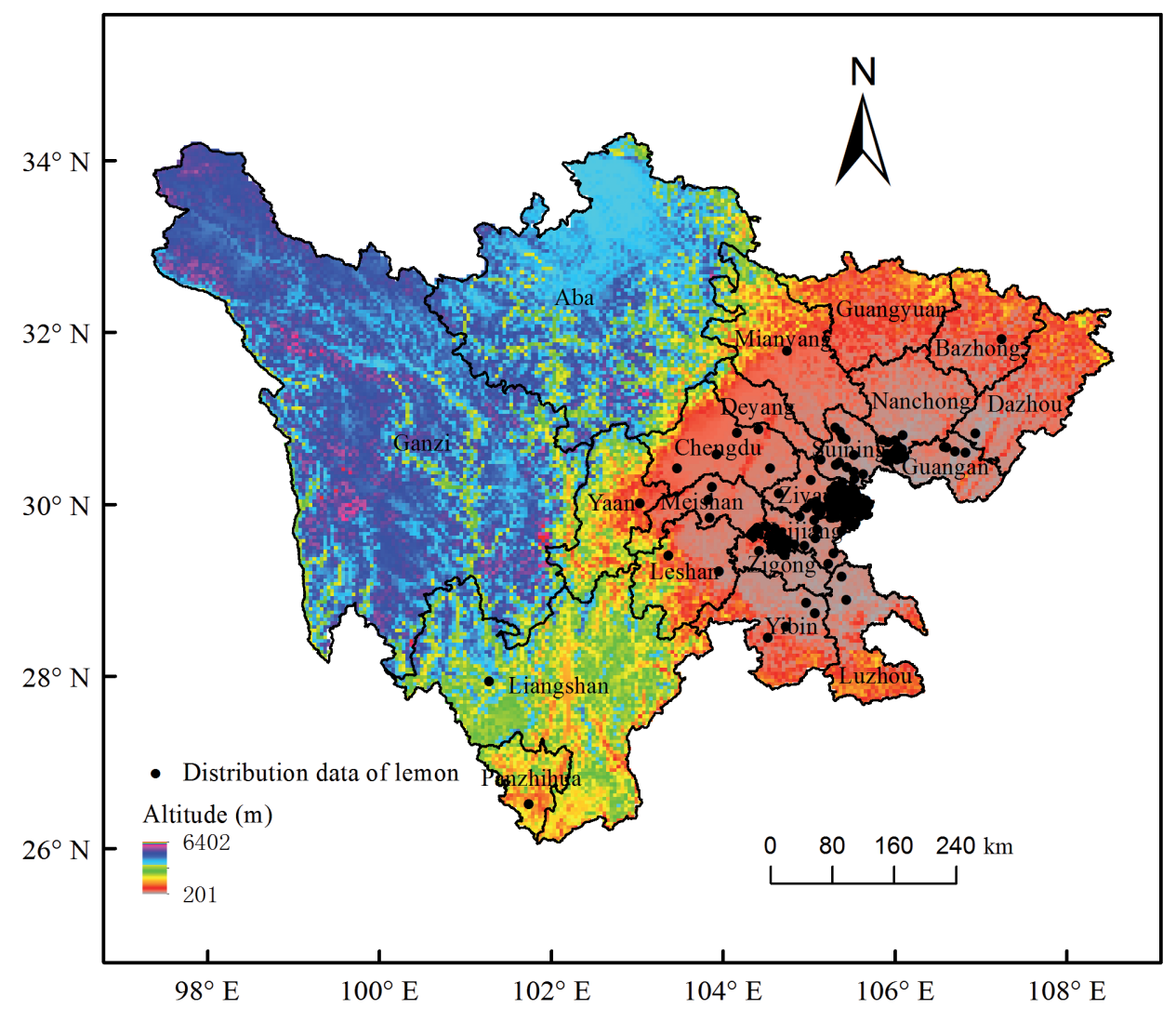

Fig. 1. Species occurrence records of lemon. 


\section{Establishment of Suitability Regionalization Indexes}

\section{Climatic Suitability Indexes}

Through literature research and expert consultation, combined with comprehensive consideration of the climatic characteristics in Sichuan Province and the demand of lemon for meteorological conditions, a total of 12 indexes are selected as potential climatic factors affecting lemon planting distribution in Sichuan Province for climatic suitability regionalization analysis. The selected indicators can be divided into five categories, including: I) Heat resources. Annual mean temperature (Tmean-A) $[2,3,25,26], \geq 10^{\circ} \mathrm{C}$ annual accumulated temperature (Tacc10) [2, 25-27] and mean temperature in January (Tmean1) $[2,26]$ II) Safe over-wintering. Mean minimum temperature in January (Tmin1) $[2,25]$ III) Soil moisture conditions. Annual precipitation (Prec-A) [2, 25, 27] and rainy days during the fruit-expanding period (from middle June to late September) (Rain-FE) [26, 27] IV) Light resources. Annual sunshine duration (Sdur) [2, 25] and sunshine duration during the mature period (from middle October to late November) (Sdur-M) [27] V) Others. Mean temperature in July (Tmean7) [19], mean temperature during the leaf-expansion period (from middle March to late March) (Tmean-LE) [25, 26], daily mean temperature during the critical flowering period (from middle April to early June) (Tmean-CF) [26, 27] and daily temperature range during the fruit-expanding period (from middle June to late September) (Tran-FE) $[26,27]$.

Research has shown that the selection of highly autocorrelated variables for modeling will have an impact on the simulation results [28]. Therefore, referring to the previous research [28-31], we choose Spearman correlation coefficient method to calculate the correlation between 12 climate variables in order to eliminate the influence of collinearity on the model modeling process and result interpretation. The attribute values of environmental variables corresponding to 132 distribution points are extracted by ArcGIS, and the correlation between variables is calculated by SPSS. When the absolute value of correlation coefficient between variables is greater than 0.85, they are considered to have strong correlation. Table 1 shows that the correlation coefficients between 12 climate variables do not exceed 0.85 . Therefore, they are selected as the dominant variables affecting lemon distribution in this study. On this basis, the MaxEnt is reconstructed, and the accuracy of simulation results is evaluated to obtain the best prediction model.

\section{Soil Suitability Indexes}

In view of the fact that lemon favors acidic soil and sandy loam, so loam and clay areas are defined as suitable regions for lemon planting, sandy loam and clay loam areas are defined as sub-suitable regions, while the sandy soil area is defined as unsuitable regions. Besides, the region with soil $\mathrm{pH} \leq 5.5$ is defined as the suitable region, those with the soil $\mathrm{pH}$ between 5.5 and 6.5 are defined as the sub-suitable regions, while those with the soil $\mathrm{pH}>6.5$ are defined as the unsuitable regions.

\section{Terrain Suitability Indexes}

A gentle slope $\left(0-30^{\circ}\right)$ towards the south or east is suitable for the planting of lemon. The reason for this is that when the slope is greater than $30^{\circ}$, the soil erosion and even landslide are more likely to occur. In addition, the sunshine duration on the slope with south or east slope aspects will be longer, thus promoting the growth of lemon and avoiding problems of wilting and quality decline caused by the direct sunlight in summer.

As the lemon prefers southward and eastward gentle slopes, the regions with slope aspects of $0-25^{\circ}, 25-30^{\circ}$ and greater than $30^{\circ}$ are defined as the suitable regions, the sub-suitable regions and the unsuitable regions for lemon planting, respectively. The regions with slope aspects of $67.5^{\circ}-112.5^{\circ}$ and $157.5^{\circ}-202.5^{\circ}$ are defined as suitable regions, regions with the slope aspects of $112.5^{\circ}-157.5^{\circ}$ are defined as sub-suitable regions, and regions with the aspect of $\leq 67.5^{\circ}$ or $\geq 202.5^{\circ}$ are defined as unsuitable regions.

\section{Suitability Analysis Method}

\section{Climatic Suitability Analysis}

With the grid data of geographic information and potential climatic factors affecting the distribution of lemon planting in Sichuan Province as the input data, the MaxEnt model outputs an estimate between 0 and 1 of probability of presence. On this basis, the climatic suitability of lemon planting in Sichuan Province is divided based on the probability distribution. The specific steps are as follows. Firstly, the ArcGIS software is used to convert the average value of selected potential climatic factors into grid data [24, 32], and export the distribution information of lemon planting sites in Sichuan Province in the CSV format, which is imported to the MaxEnt software. Secondly, considering the influence of potential climate factors on lemon planting, the potential climate model for lemon planting is constructed, and the simulation accuracy is further evaluated [14, 33, 34]. Thirdly, the Jackknife method is adopted to estimate the importance of each potential climatic factor, among which the dominant factors affecting the distribution of lemon planting are determined. The climate model for the distribution of lemon planting in Sichuan Province is reconstructed, and the accuracy of simulation results is evaluated as well. Fourthly, based on the extracted dominant climatic factors in the previous step and by referring to the classification criteria about the possibility assessment in the Intergovernmental Panel on Climate Change report 


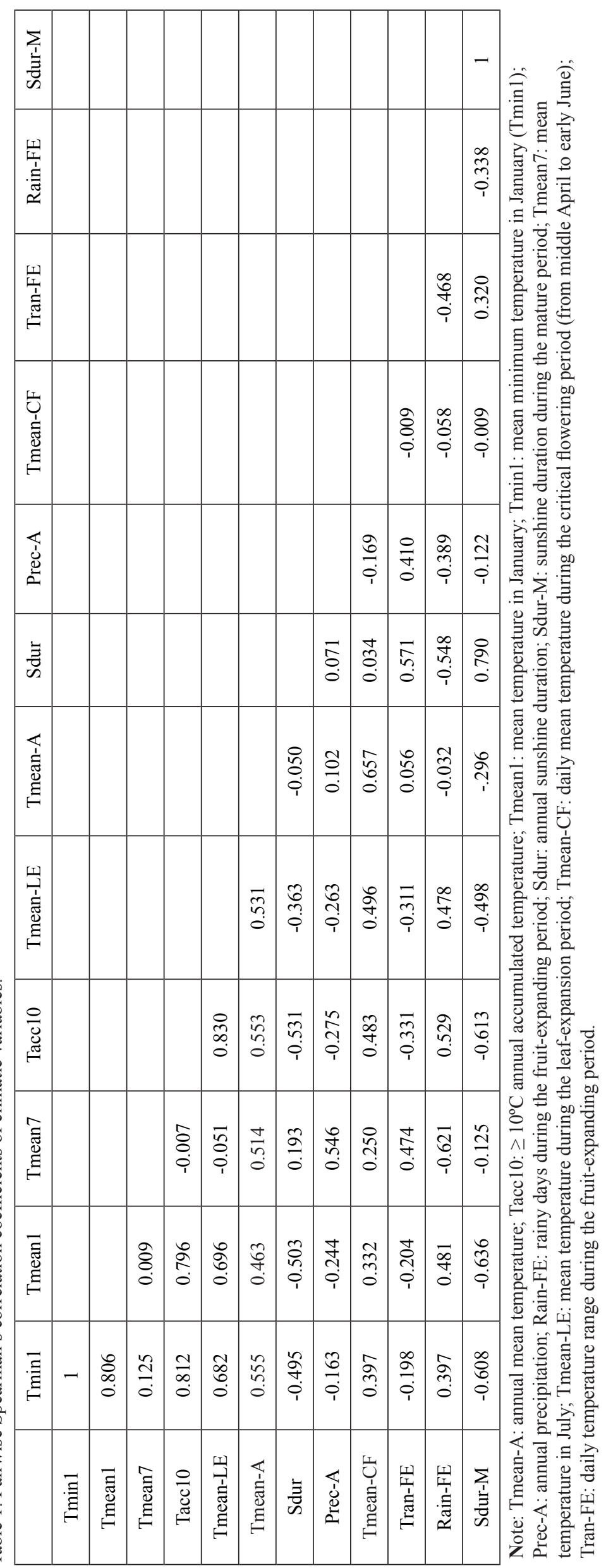


[35], the climate suitable regions for lemon planting in Sichuan Province are identified. Finally, according to the sensitive characteristic curve output by the MaxEnt software, the suitable ranges of each dominant climate factor in different climate suitable regions are determined.

\section{Ecological Suitability Analysis Method}

Based on the comprehensive consideration of the influence of climate factors, soil factors and terrain factors on the growth distribution of lemon, and combined with the weight of each factor, the distribution model of ecological suitability regionalization of lemon planting in Sichuan Province is established.

Since the regionalization indexes are divided into three categories of climate, soil and terrain, by referring to the research on the refined regionalization of ecological suitability of lemon planting in Yunnan Province [2] and combined with the actual situation of lemon planting in Sichuan Province [25], the weight of each index is assigned as follows. The weight is set to 0.7 for climate indexes $(0.14$ for the mean temperature in July, 0.14 for the annual mean temperature, 0.14 for the sunshine duration during the mature period, 0.14 for $\geq 10^{\circ} \mathrm{C}$ accumulated temperature, 0.14 for the average minimum temperature in January), 0.2 for soil indexes ( 0.1 for the soil types and 0.1 for the soil $\mathrm{pH}$ value), and 0.1 for terrain indexes $(0.05$ for the slope aspect and 0.05 for the slope).

On this basis, the regionalization model is established as follows.

$$
P=\sum_{\mathrm{i}=1}^{\mathrm{j}} \mathrm{q}_{\mathrm{i}} A_{\mathrm{i}}
$$

where $P$ represents the score of regionalization model, $\mathrm{q}_{\mathrm{i}}$ represents the regionalization index, $A_{\mathrm{i}}$ represents the corresponding weight of each regionalization index, and $\mathrm{j}$ represents the total number of regionalization indexes.

\section{Refined Ecological Suitability Regionalization}

Based on the MaxEnt model, the climatic suitability regionalization is obtained through the analysis of climatic factors. Furthermore, by using the ArcGIS software, the terrain suitability regionalization and soil suitability regionalization are obtained through the analysis of terrain data and soil data. Then, the

Table 2. The AUC value simulated by the potential distribution model of lemon planting in Sichuan Province.

\begin{tabular}{|c|c|}
\hline \multicolumn{2}{|c|}{ AUC value } \\
\hline $\begin{array}{c}\text { Based on potential climatic } \\
\text { factors }\end{array}$ & $\begin{array}{c}\text { Based on dominant climatic } \\
\text { factors }\end{array}$ \\
\hline 0.964 & 0.938 \\
\hline
\end{tabular}

raster data are calculated and classified according to section 1.4.2, and the refined ecological suitability regionalization map is finally obtained [36-38].

\section{Results and Discussion}

\section{Climatic Suitability Analysis}

\section{Accuracy Evaluation of Initial Model Simulation}

The results show that the area under curve (AUC) based on potential climatic factors is 0.964 (Table 2, Fig. S1), that is, the accuracy of the initial model reaches the "excellent" level, indicating that the model can be used to simulate the potential distribution of lemon planting in Sichuan Province.

\section{Selection Analysis of Dominant Climatic Factors}

Table 3 shows that the contribution rates of eight climate factors mean temperature in July, daily temperature range during the fruit-expanding period, sunshine duration during the mature period, annual precipitation, average minimum temperature in January, annual mean temperature, $\geq 10^{\circ} \mathrm{C}$ annual accumulated temperature and rainy days during the fruit-expanding period) to the modeling are $52.7 \%, 16.6 \%, 10.1 \%$, $7.5 \%, 4.6 \%, 4.3 \%, 1.6 \%$ and $1.5 \%$, respectively. The cumulative contribution rate reaches $98.9 \%$, which is significantly higher than the other four climatic factors. Among them, the permutation importance of daily temperature range and rainy days during the fruitexpanding period, average minimum temperature in January, annual mean temperature, annual precipitation,

Table 3. Contribution rate and permutation importance of climatic factors to model simulations.

\begin{tabular}{|c|c|c|}
\hline $\begin{array}{c}\text { Potential climatic } \\
\text { factors }\end{array}$ & $\begin{array}{c}\text { Contribution rate } \\
(\%)\end{array}$ & $\begin{array}{c}\text { Permutation } \\
\text { importance (\%) }\end{array}$ \\
\hline Tmean7 & 52.7 & 3 \\
\hline Tran-FE & 16.6 & 59.4 \\
\hline Sdur-M & 10.1 & 3 \\
\hline Prec-A & 7.5 & 6.3 \\
\hline Tmin1 & 4.6 & 8.8 \\
\hline Tmean-A & 4.3 & 8.5 \\
\hline Tacc10 & 1.6 & 0.6 \\
\hline Rain-FE & 1.5 & 9 \\
\hline Sdur & 0.9 & 0.9 \\
\hline Tmean-CF & 0.2 & 0.5 \\
\hline Tmean-LE & 0 & 0 \\
\hline Tmean1 & 0 & 0 \\
\hline
\end{tabular}


mean temperature in July and sunshine duration during the mature period are $59.4 \%, 9 \%, 8.8 \%, 8.5 \%, 6.3 \%$, $3 \%$ and $3 \%$, respectively, which play an important role in the modeling process.

Fig. 2 shows that the training gain of annual mean temperature exceeds 1.4, which contributes the most to the lemon planting distribution. The climatic factors of average minimum temperature in January, $\geq 10^{\circ} \mathrm{C}$ annual accumulated temperature, sunshine duration during the mature period and mean temperature in July all have a training score of exceeding 1.2, which are of great importance for the distribution of lemon planting. Therefore, the abovementioned climatic factors (annual mean temperature, average minimum temperature in January, $\geq 10^{\circ} \mathrm{C}$ annual accumulated temperature, the sunshine duration during the mature period and the mean temperature in July) are determined as the dominant climatic factors affecting the distribution of lemon planting.

According to the extracted dominant climatic factors, the MaxEnt model is used to reconstruct the simulation model for potential distribution of lemon planting in Sichuan Province. Table 2 shows that the AUC of the model based on dominant climatic factors reaches 0.938 , that is, the accuracy of the simulation result reaches the "excellent" standard, indicating that this reconstructed model can be used to simulate the potential distribution of lemon planting in Sichuan Province.

Various factors including the climate, soil, terrain, hydrology, biology and human activities affect the distribution of species. The representativeness and integrity of selected environmental variables are the keys to determine the accuracy of evaluation results of the MaxEnt model. However, the correlations among environmental variables will introduce redundant information that makes the model more complex, resulting in unpredictable deviations in the simulation results. Based on the Spearman correlation analysis, pairwise environmental variables with correlation coefficient greater than 0.8 , low biological significance and low contribution rate are eliminated, which can effectively avoid the above problems.

\section{Analysis of Dominant Climatic Factors Affecting the Lemon Planting Distribution}

The response curves in Fig. 3 show that the probability distribution curves of five dominant climatic factors present only one peak, which are all in accord with the Poisson distribution. The appropriate value of mean temperature in July is $26-28^{\circ} \mathrm{C}$, and the most appropriate value is $27^{\circ} \mathrm{C}$. When the mean temperature in July ranges between $26^{\circ} \mathrm{C}$ and $27^{\circ} \mathrm{C}$, the distribution probability of lemon planting increases with the mean temperature in July, and it decreases with the increase of mean temperature in July when it is between $27^{\circ} \mathrm{C}$ and $28^{\circ} \mathrm{C}$. The appropriate value of annual mean temperature is $17-19^{\circ} \mathrm{C}$, with the most appropriate value being $18^{\circ} \mathrm{C}$. When the annual mean temperature is between $17^{\circ} \mathrm{C}$ and $18^{\circ} \mathrm{C}$, the distribution probability of lemon planting increases with the increase of annual mean temperature, and decreases with the increase of annual mean temperature when it is between $18^{\circ} \mathrm{C}$ and $19^{\circ} \mathrm{C}$. The appropriate value of the average minimum temperature in January is $4-6^{\circ} \mathrm{C}$, with the most appropriate value being $5^{\circ} \mathrm{C}$. When the average minimum temperature in January ranges between $4^{\circ} \mathrm{C}$ and $5^{\circ} \mathrm{C}$, the distribution probability of lemon planting increases with its increase, and decreases with its increase when it is between $5^{\circ} \mathrm{C}$ and $6^{\circ} \mathrm{C}$. The appropriate value of $\geq 10^{\circ} \mathrm{C}$ annual accumulated temperature is $5600-6200^{\circ} \mathrm{C}$, and the most appropriate value is $5900^{\circ} \mathrm{C}$. When $\geq 10^{\circ} \mathrm{C}$ annual accumulated temperature is between $5600^{\circ} \mathrm{C}$

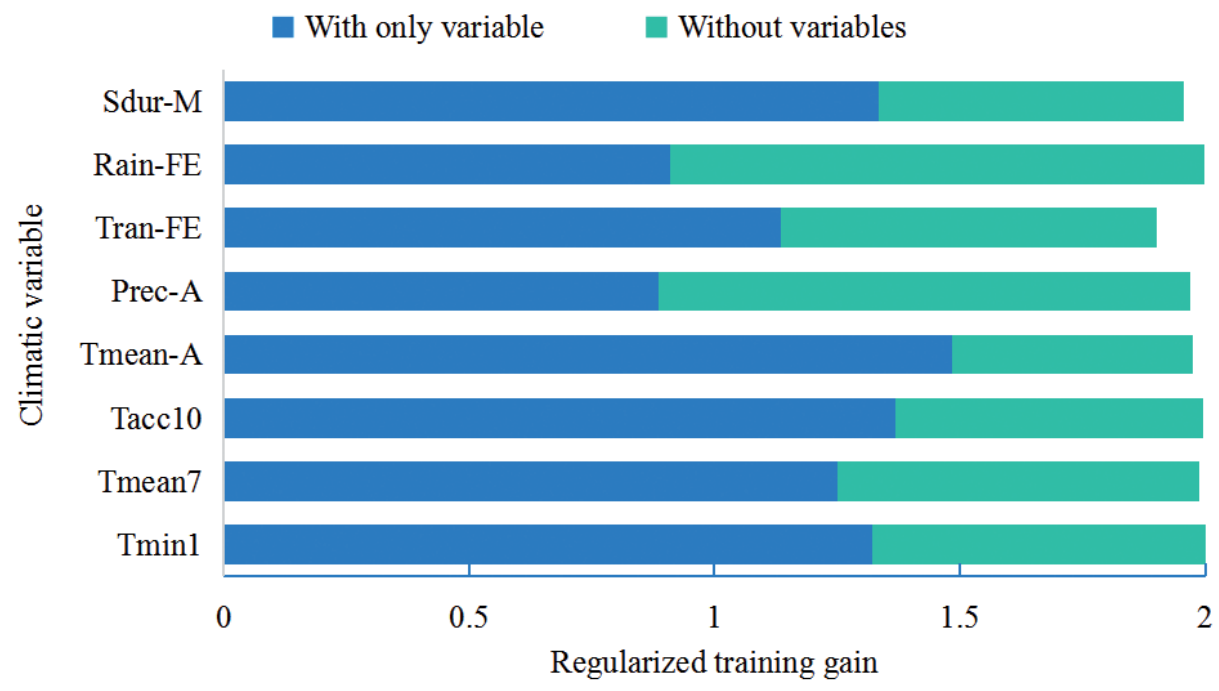

Fig. 2. Importance of environmental variables to lemon by jackknife analysis. Blue bar represents the regularized training gain for models using a single variable only, while green represents the jackknife without that single variable. 

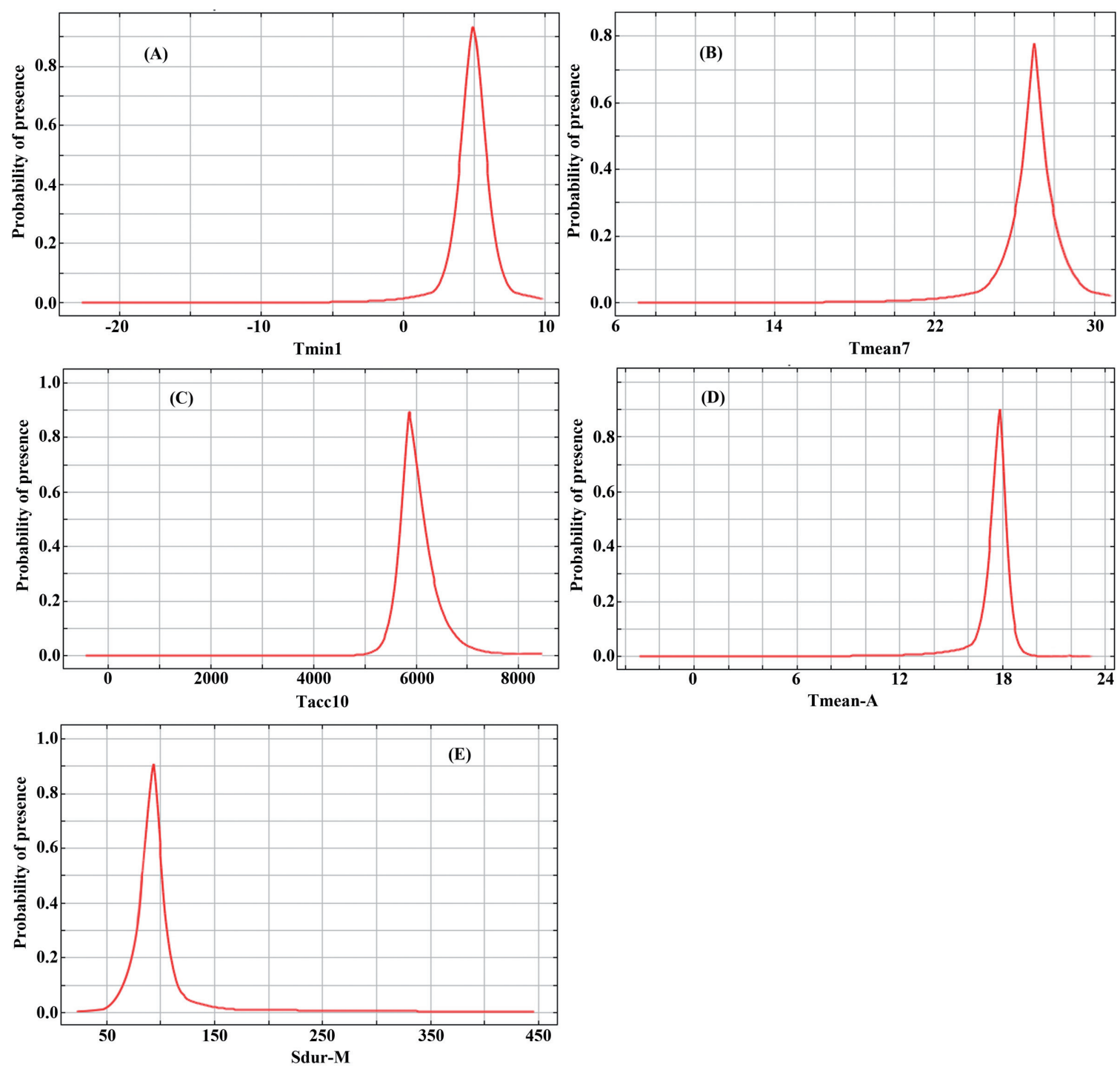

Fig. 3. Curves of the suitability probability for lemon planting under different climatic conditions, that is, sensitive characteristic curves exported by the MaxEnt model. (A): mean minimum temperature in January (Tmin1), (B): mean temperature in July (Tmean7), (C): $\geq 10^{\circ} \mathrm{C}$ annual accumulated temperature (Tacc10), (D) annual mean temperature (Tmean-A), (E): sunshine duration during the mature period (Sdur-M).

and $5900^{\circ} \mathrm{C}$, the distribution probability of lemon planting increases with its increase, and decreases with its increase when it is between $5900^{\circ} \mathrm{C}$ and $6200^{\circ} \mathrm{C}$. The appropriate value of sunshine duration during the mature period is $60-102$ hours, and the most appropriate value is 90 hours. When the sunshine duration during the mature period is between 60 hours and 90 hours, the distribution probability of lemon planting increases with its increase, and decreases with its increase when it is between 90 hours and 102 hours.

Lemon is the most cold-intolerant species in citrus fruit trees. It prefers the climate of warm winter and cool summer, and requires the annual mean temperature above $17^{\circ} \mathrm{C}$ and the coldest monthly mean temperature above $6.5^{\circ} \mathrm{C}[2,39]$. Through the MaxEnt model, it is found that the environment with annual mean temperature lower than $17^{\circ} \mathrm{C}$ and the minimum temperature in January lower than $4^{\circ} \mathrm{C}$ is not conducive to the existence of lemon. The increases of annual mean temperature and the minimum temperature in January can significantly increase the existence probability of lemon, indicating that low temperature would significantly reduce the distribution probability of lemon, which is consistent with the cold-intolerant growth habit of lemon. The predictions in this study show that the most suitable regions for lemon planting in Sichuan Province are mainly distributed between $29.2^{\circ} \mathrm{N}$ and $31.3^{\circ} \mathrm{N}$. This region belongs to warm subtropical climate, with warm winter and small annual temperature differences, which is highly consistent with the habit of preferring warm winter and cool summer for lemon. It also indicates the accuracy and scientificity of suitable planting areas predicted by the MaxEnt model. 


\section{Climate Suitability Regionalization of Lemon Planting in Sichuan Province Based on the MaxEnt Model's Simulation}

Based on the simulation results from the reconstructed MaxEnt model by the dominant climatic factors, the predicted potential distribution of lemon planting are divided into regions with different suitability grades by referring to the classification standard of climatic suitability.

The results in Fig. 4 show that the highly suitable climatic regions for lemon planting have the characteristic of concentrated distribution, with the land area of about $94,000 \mathrm{~km}^{2}$, accounting for $20 \%$ of the land area of Sichuan Province. Highly suitable regions are mainly distributed in Neijiang City, Ziyang City, Meishan City, Suining City, Nanchong City and Guang'an City. While other highly suitability regions are dispersedly distributed in Leshan City, Ya'an City, Yibin City, Chengdu City, Mianyang City, Deyang City, Panzhihua City, etc. In the main producing counties for lemon in Sichuan Province, the area sizes of highly suitable regions are Neijiang City, Ziyang City, Guang'an City, Nanchong City, Meishan City and Zigong City in a descending order.

The moderately suitable climate region for lemon planting cover a wide range with a large north-south span. Among them, the moderately suitable climate regions show a concentrated distribution in the north part, which are slightly scattered in the south. The land area of moderately suitable climate regions is about $58,000 \mathrm{~km}^{2}$, accounting for $12 \%$ of the total of Sichuan Province. They cover most areas in Suining City, Neijiang City and Zigong City, as well as Dazhou City, Guang'an City, Nanchong City, Luzhou City and Yibin
City. The area sizes of moderately suitable regions are Suining City, Neijiang City, Zigong City, Nanchong City, Dazhou City, Guang'an City, Luzhou City and Yibin City in a descending order. The moderately suitable climate region surrounds the highly suitable climate regions closely (Fig. 4).

Most areas in the eastern Sichuan Province are slightly suitable regions for lemon planting, covering a large area. Meanwhile, a small part in the southern and areas scattered in central Sichuan Province are also included. The land area of slightly suitable regions is about $39,000 \mathrm{~km}^{2}$, accounting for $8 \%$ of the total of Sichuan Province. The regions of more than half of the Panzhihua City in the southern Sichuan are slightly suitable for lemon planting. In addition, the southwestern part of Liangshan Yi Autonomous Prefecture connecting to the above regions is also slightly suitable. In the eastern part of Sichuan Province, the slightly suitable regions with a circular distribution are mainly concentrated in Guang'an City, Dazhou City, Bazhong City, Nanchong City, Guangyuan City, Mianyang City, Deyang City, Chengdu City, Meishan City, Leshan City, Yibin City and Luzhou City in an anticlockwise direction. Besides, the slightly suitable regions are also scattered in parts of the central Ya'an City and the eastern Liangshan Yi Autonomous Prefecture (Fig. 4).

Most areas of both the northern and western Sichuan as well as parts of the southern Sichuan are unsuitable for lemon planting, with the land area of about $290,000 \mathrm{~km}^{2}$, accounting for $60 \%$ of the total of Sichuan Province. The western Sichuan Plateau is also not suitable for the lemon planting due to the low temperature, more frost and snow as well as less rainfall, especially the extremely low temperature in winter.

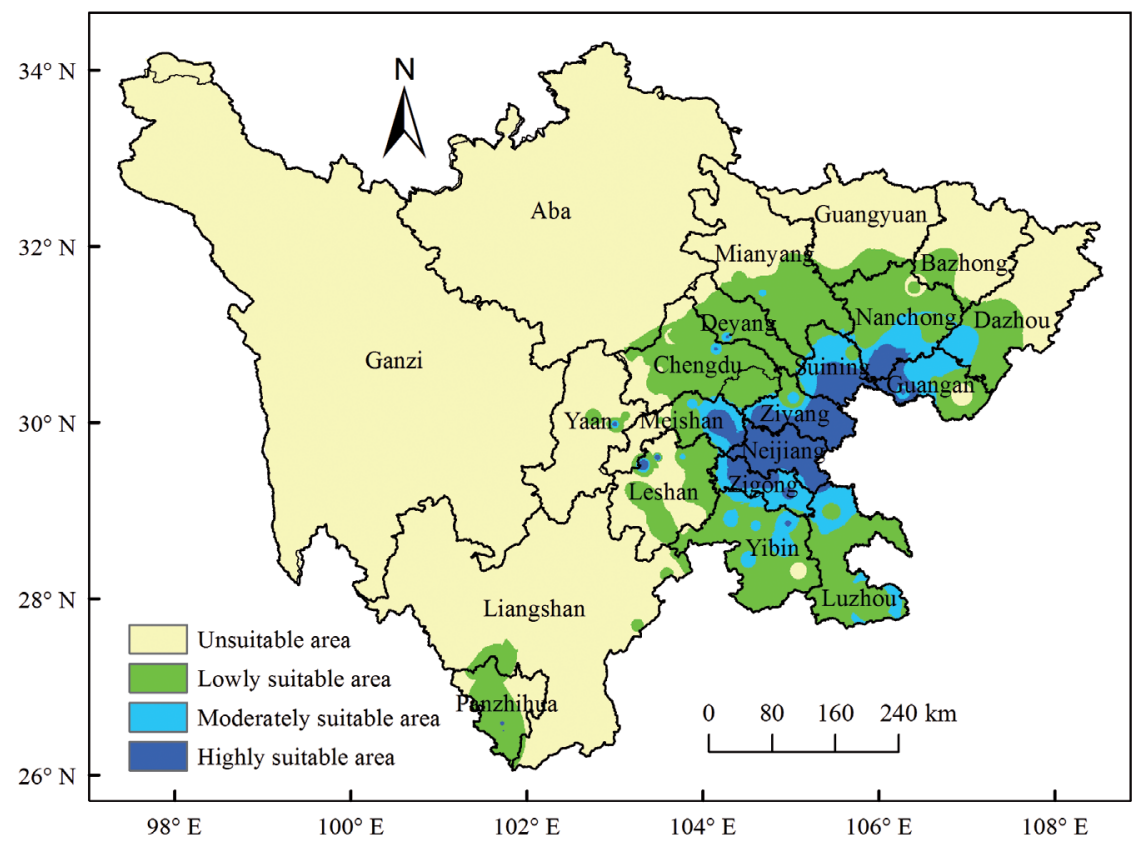

Fig. 4. Climate suitability regionalization of lemon planting in Sichuan Province based on the MaxEnt model. 
Besides, the mountainous area in northern Sichuan is not suitable for lemon planting due to the cold winter and cool summer, where natural disasters especially drought and flood frequently occur. Considering the actual geographical distribution and the weight of each climatic factor affecting the lemon planting, the soil and terrain suitability analysis is no longer carried out for unsuitable climatic regions (Fig. 4).

Previous studies on lemon are mostly focused on physiological and biochemical characteristics [40-42], variety selective breeding [43, 44], disease and pest control [45-47], etc. However, relatively little research have been made on its large-scale potential geographical distribution and niche analysis. The MaxEnt is a prediction model based on the maximum entropy principle, which believes that the thing with the maximum entropy is closest to its real state under known conditions. With the species distribution and environmental data as the input, the model can find the maximum entropy of species distribution rules, so that the potential distribution of species can be predicted. It has already been widely used in the prediction of potential distribution of biological species. Petitpierre et al. [48] applied the niche model to verify the niche conservation of invasive species, and found that the MaxEnt software is an effective tool for this study and it is suitable for analyzing the relationship between the geographical distribution of species and the climate. Elith et al. [49] compared the simulation performances of various niche models, and revealed that the MaxEnt model has the highest prediction accuracy among the 16 models. Therefore, in this study the MaxEnt model is selected as the simulation software to predict the potential distribution of lemon in Sichuan, and the influence of environmental variables on its distribution is analyzed.

The predicted potential geographical distribution of species based on the MaxEnt model mainly involves the geographical distribution information of species and the corresponding climatic data, so the data quality will have a certain impact on the simulation results [50-52]. On the one hand, the distribution sites collected through field investigations are often areas easily accessible, and the distribution information recorded in literature and specimen databases may also have problems such as old age, inconsistency and unclear latitude and longitude coordinates, which will affect the simulation accuracy. On the other hand, factors such as human disturbance, ecological factors, species evolution ability, diffusion ability and interspecific competition will directly or indirectly affect the simulation results. Studies have shown that the sampling range and sample capacity are the critical factors to determine the reliability of the simulation results of species distribution model $[11,53]$. The larger the sample capacity and the wider the sampling area, the more information about the relationship between species and environment will be obtained, and the higher the estimation accuracy of the species distribution model will be $[54,55]$. In this study, the distribution data of lemon planting in Sichuan is obtained by field investigation, querying the species distribution database and consulting relevant literatures, which can not only represent the habitat in its distribution area, but also avoid the biases of simulation results caused by sample problems. This study shows that the AUC values of the MaxEnt model based on potential climatic factors and dominant climatic factors are 0.964 and 0.938 , respectively, indicating that the prediction results reach a very accurate level, and thus the model can be well applied for the prediction of lemon geographical distribution.

\section{Soil Suitability Analysis}

The distribution of soil texture in Sichuan Province is shown in Fig. 5a). The soil textures of regions in red and orange are loam, clay, sandy loam and clay loam. The soil with these textures is suitable for lemon planting, mainly distributed in Dazhou City, Bazhong City, Guangyuan City, Nanchong City, Mianyang City, Deyang City, Suining City, Chengdu City, Ziyang City, Neijiang City, Yibin City, Zigong City, Leshan City and Luzhou City. However, the sandy soil is not suitable for lemon planting, which is concentrated in borer areas of multiple cities, including Guangyuan City, Bazhong City, Mianyang City, Deyang City, Chengdu City, Ya'an City, Leshan City and the Panzhihua City.

The distribution of soil $\mathrm{pH}$ value in Sichuan Province is shown in Fig. 5b). The regions with strongly acidic soil (soil $\mathrm{pH} \leq 5.5$ ) suitable for lemon planting are scattered in every city, mainly concentrated in Ya'an City, Leshan City, Neijiang City, Luzhou City and Panzhihua City. The area with soil $\mathrm{pH}$ between 5.5 and 6.5 is sub-suitable for lemon planting, with relatively continuous distribution in Ya'an City, Mianyang City, Deyang City, Chengdu City, Meishan City and Leshan City. The regions with neutral or alkaline soil (soil $\mathrm{pH}>6.5$ ) which are not suitable for lemon planting are mainly distributed in the basin margin.

Fig. 5c) shows the comprehensive regionalization of soil suitability for lemon planting in Sichuan Province. The highly suitable regions are mainly distributed in central Sichuan Basin, where the soil texture is mainly loam and clay with soil $\mathrm{pH} \leq 5.5$. The sandy loam and clay loam with $\mathrm{pH}$ values $\leq 5.5$ in borer areas of multiple cities (Bazhong City, Dazhou City, Ya'an City, Yibin City and Luzhou City) are moderately suitable for lemon planting. Other regions are slightly suitable or unsuitable for lemon planting due to unsatisfied soil and $\mathrm{pH}$ conditions.

\section{Terrain Suitability Analysis}

The slope distribution in Sichuan Province is shown in Fig. 6a). As for lemon planting, the area with gentle slopes of $0^{\circ}-25^{\circ}$ is suitable, the area with slopes of $25^{\circ}-30^{\circ}$ is sub-suitable, and the area with slopes greater than $30^{\circ}$ is not suitable. The western parts of Sichuan 

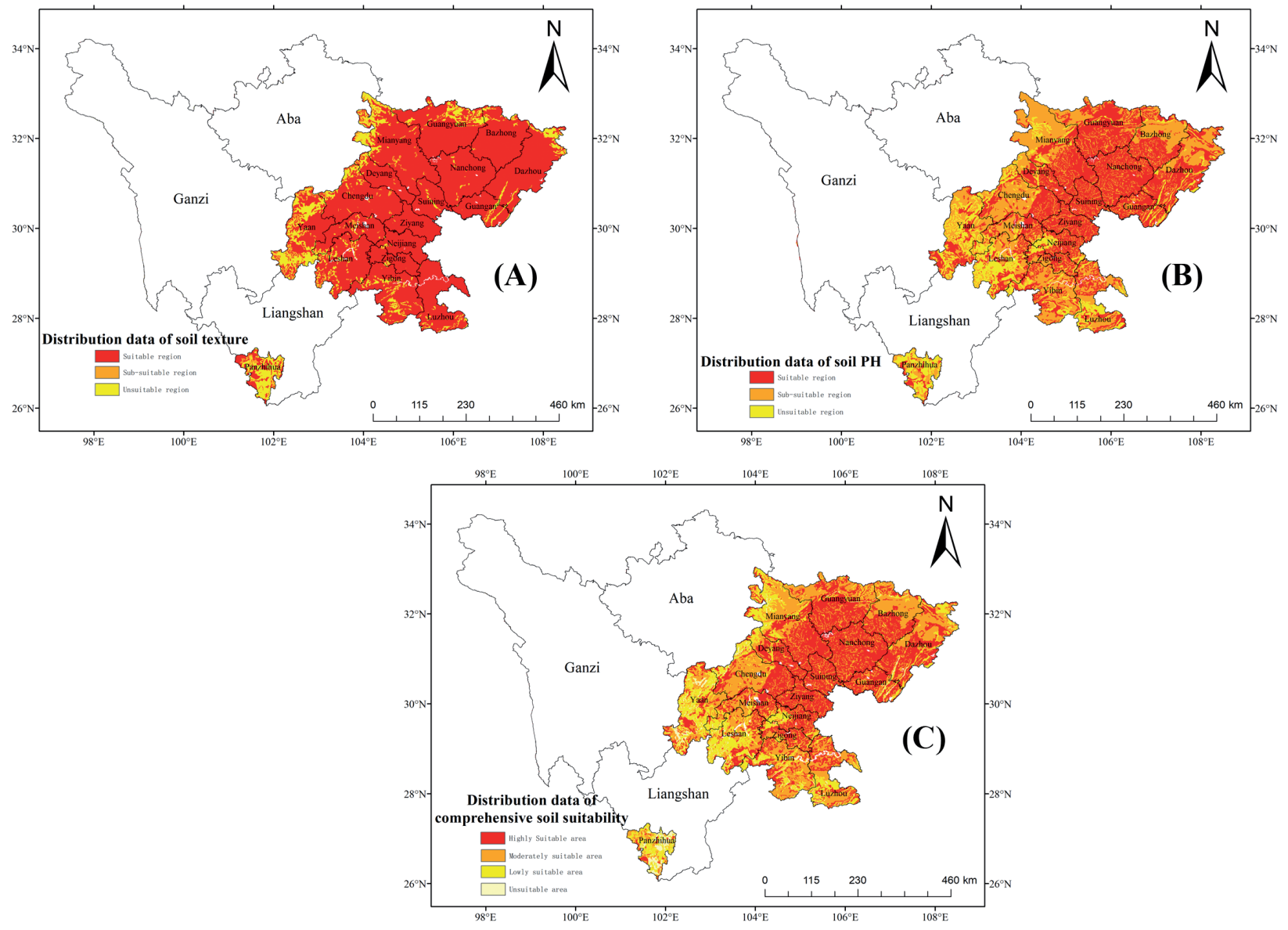

Fig. 5. Soil suitability analysis of lemon planting in Sichuan Province. a) Distribution data of soil texture, b) Distribution data of soil PH, c) Distribution data of comprehensive soil suitability.

Province are mostly plateau or mountainous regions with high altitudes, while the eastern part is basin area. The regions with slopes of $0^{\circ}-25^{\circ}$ are mainly concentrated in the basin area of eastern Sichuan Province, including Guangyuan City, Bazhong City, Dazhou City, Deyang City, Nanchong City, Guang'an City, Mianyang City, Suining City, Chengdu City, Ziyang City, Meishan City, Neijiang City, Leshan City, Zigong City, Yibin City and Luzhou City.

Fig. 6b) gives the distribution of slope aspects in Sichuan Province. The regions with the aspects towards the south and the east (shaded in red and orange) are suitable for lemon planting. The sunshine duration on these slopes will be longer, which will promote the lemon growth, while the slope with aspect toward the north is not suitable for lemon planting. Overall, the slopes with the aspects towards the south, east-west and north are evenly distributed in every city of Sichuan Province.

Comprehensive terrain suitability regionalization of lemon planting in Sichuan Province in Fig. 6c) shows that the highly suitable and moderately suitable regions have gentle slopes facing southward or east-westward, mainly concentrated in the basin area of eastern Sichuan Province and in Panzhihua City as well.
The moderately suitable and slightly suitable regions are mainly distributed in the border area of the basin, with relatively continuous distribution, where the slope aspect and slope conditions are not favorable for lemon planting.

\section{Ecological Suitability Analysis}

Fig. 7 shows the ecological suitability regionalization of lemon planting in Sichuan Province. The ecological suitability of lemon planting in Sichuan Province is classified into highly suitable, moderately suitable, slightly suitable and unsuitable grades. The area for region of each grade is obtained through the area calculation tool in the ArcGIS software.

The highly suitable regions with an area of $29,000 \mathrm{~km}^{2}$ are mainly concentrated in Guang'an City, Nanchong City, Suining City, Ziyang City, Neijiang City and Zigong City. Some regions scattered in basin areas are also included. In addition, there are also some highly suitable sites in Panzhihua City for lemon planting. The area of moderately suitable region is $39,000 \mathrm{~km}^{2}$, with most regions distributed in the mountainous areas of the eastern basin, such as Guang'an City, Dazhou City, Suining City and Zigong City. The slightly 

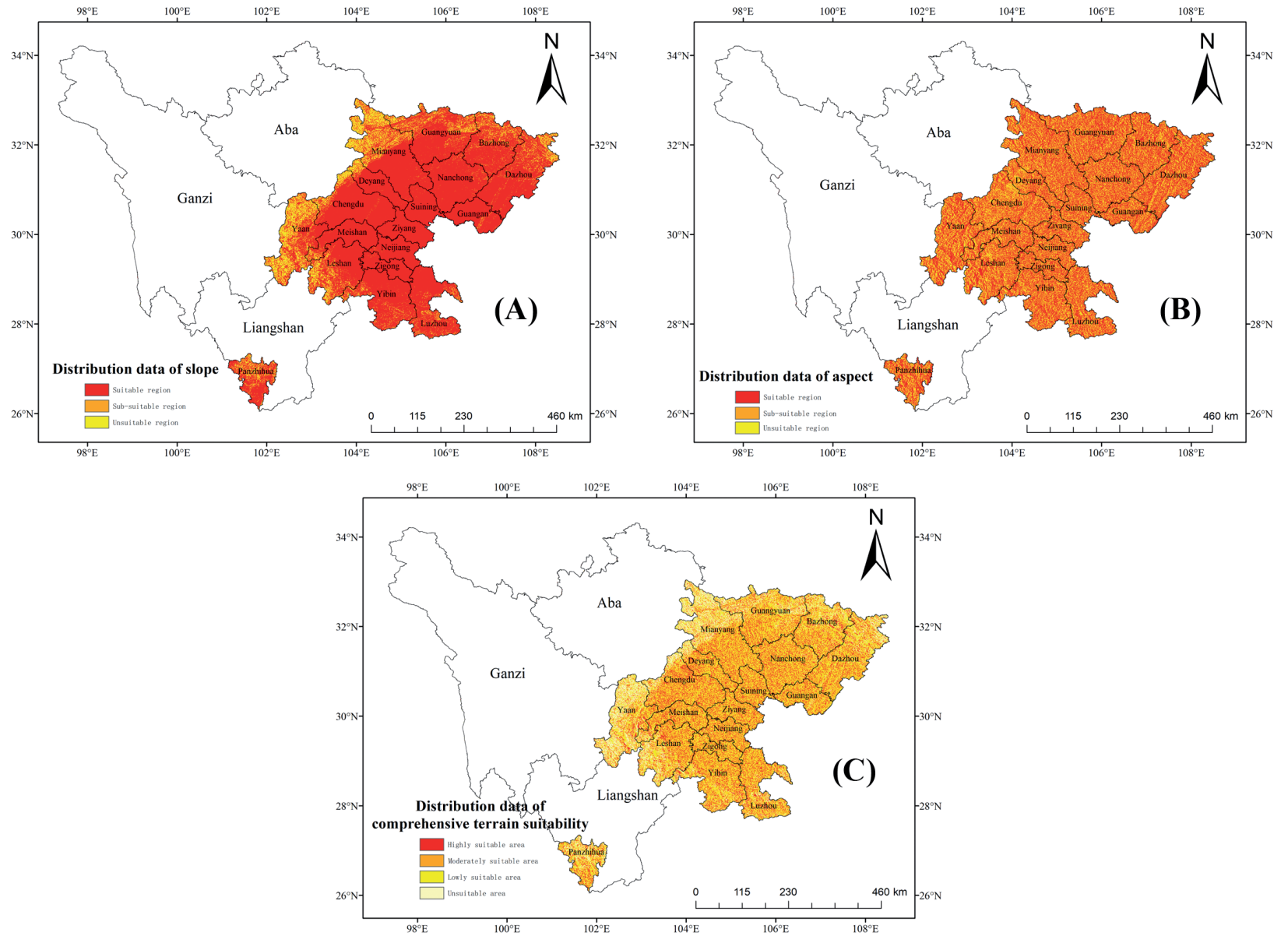

Fig. 6. Terrain suitability analysis of lemon planting in Sichuan Province. a) Distribution data of slope, b) Distribution data of aspect, c) Distribution data of comprehensive terrain suitability.

suitable regions with an area of $67,000 \mathrm{~km}^{2}$ are mainly concentrated in central Sichuan, surrounding the highly suitable and moderately suitable regions. The unsuitable region covers an area of $53,000 \mathrm{~km}^{2}$, mainly concentrated in the plateau and mountainous regions of western and northern Sichuan.

Currently, the lemons in Sichuan Province are mainly planted in Anyue County of Ziyang City,

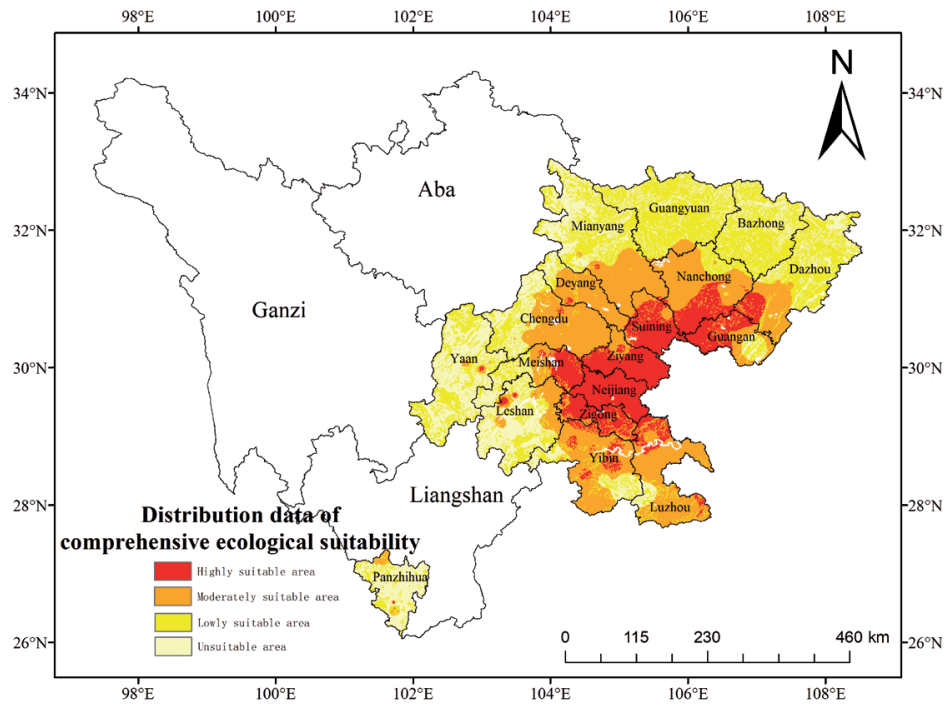

Fig. 7. Ecological suitability analysis of lemon planting in Sichuan Province. 
with the highest ranked yield and planting area in China. Prediction and analysis on the suitability of lemon planting in the target area before introduction can not only avoid the problems of single species and susceptible to plant diseases and insect pests due to the lack of reasonable planning, but also help to optimize the lemon industrial structure, which is of practical significance for scientific layout and avoiding the loss caused by blind introduction. The prediction results in this study show that the most suitable regions for lemon planting in Sichuan Province are mainly located in Guang'an City, Nanchong City, Suining City, Ziyang City, Neijiang City and Zigong City, which is highly consistent with the current situation that Ziyang City is the main production area of lemon in Sichuan. This study also indicates that lemon can be introduced to other regions in Sichuan except the Anyue City according to the local conditions. For Anyue City, the planting scale should be appropriately controlled, focusing on improving the quality and economic benefits.

According to different climate scenarios released by IPCC, the geographical distribution of fruit trees in the future can be estimated, which can provide a scientific theoretical reference for the introduction, promotion and planting layout of fruit trees. Wang et al. used MaxEnt model to simulate the geographical distribution of Actinidia chinensis in China under the future RCP scenario, which provided a critical reference for its plantation pattern and countermeasure to cope with climate change in China [56]. Fan et al. compared the changes of geographical distribution of Rosa roxburghii in China in current, 2050s and 2070s under RCP4.5 and RCP8.5 scenarios based on MaxEnt [57]. There are many environmental factors affecting the growth and distribution of fruit trees, such as climate, soil type, vegetation type, topographic factor, variety type, biotic interactions and human activities [58-60]. In addition to climate variables, the future changes of most other variables cannot be evaluated quantitatively at present. Therefore, in order to reduce the complexity of the model, this study did not simulate the changes of lemon geographical distribution in the future. In the next work, we should focus on the interaction between target species and other factors, the lag phenomenon of species distribution on climate change, the change of soil and vegetation types and the impact of human activities, so as to evaluate the effects of climate change on lemon distribution.

\section{Conclusions}

Phenotypic plasticity and local adaptability are important factors affecting the geographical distribution of species, and how to combine them with SDM is the key to improve the prediction ability of the model. Garzón et al. incorporated plasticity and local adaptation into a SDM by calibrating models of tree survivorship with adaptive traits in provenance trials, and they confirmed the importance of considering adaptive traits when predicting species distributions [61]. Stahl et al. explained the climate ranges of 250 North American tree species distributed from the boreal to the subtropics using five key plant functional traits, and the result showed that the implementation of trait-based climatic constraints has the potential to predict both range shifts and ecosystem consequences on a more functional basis [62]. In this study, due to the lack of experimental data, phenotypic plasticity and local adaptability cannot be embedded into climate variables, which needs further improvement. However, the regionalization analysis of ecological suitability of lemon planting in Sichuan Province combines the three factors of climate, soil and terrain. Through the combination of the MaxEnt model and the ArcGIS technology, an intuitive and analyzable suitability regionalization map is formed. Compared with previous studies on the lemon suitability regionalization, the influencing factors considered in this study are more comprehensive, the regional scope is wider, and the analysis results are more detailed and intuitive. This not only avoids the problems of single species and weak resistance to plant diseases and insect pests due to the lack of reasonable planning, but also helps to optimize the industrial structure of lemon for effective and reasonable planting. The deficiency of this study is that the results can only represent area with similar environmental conditions as the study region. However, as the distribution of lemon planting is also affected by social and economic needs, improvement of agricultural conditions, humanities, genetic variation of lemon fruit and other factors, there may be some deviations between the predicted results and the actual situations. Based on the prediction results in this study, lemon can be planted in highly and moderately suitable regions to verify the predicted results in the future.

\section{Author Contributions}

Yanyan Liu planned and supervised the project. Yanyan Liu and Rulin Wang, performed the experiments, analyzed the data, contributed reagents/ materials/analysis tools. Huan Liu, Xu Xin, Yujia Zou and Yufang Zhang contributed to data collection and evaluation.

\section{Acknowledgments}

This work was funded by the Tibetan Plateau Scientific Expedition and Research Program (STEP) (2019QZKK0608), and the Science and Technology Department of Sichuan Province, China (2020YJ0359). 


\section{Conflicts of Interet}

The authors declare no conflicts of interest.

\section{References}

1. KANG C.Z., ZHOU T., GUO L.P., HUANG L.Q., ZHU S.D., XIAO C.H. Ecological suitability and regionalization of Pseudostellaria heterophylla (Miq.) Pax ex Pax et Hoffm. in China. Acta Ecologica Sinica, 36, 2934, 2016 [In Chinese].

2. ZHANG M.D., LIU P.Y., HU X.Q., DUAN C.C. Ecological suitability fine regionalization of lemon planting in Yunnan. Chinese Journal of Agricultural Resources and Regional Planning, 40, 196, 2019 [In Chinese].

3. ZHU Y., DUAN Y.H., PAN G.Y., JIANG T. Effects of environment and meteorological disasters on lemon growth in Liannan county. Biological Disaster Science, 38, 371, 2015 [In Chinese].

4. GAO Y.H., CHEN Z.J., JU H., YANG S.Q., TANG Y.H. GIS-based fine climate ecological zoning of sweet orange in the three gorges reservoir area. Journal of Southwes University (Natural Science Edition), 31, 1, 2009 [In Chinese].

5. LI B., ZHANG F., ZHANG L.W., HUANG J.F. Comprehensive suitability evaluation of tea crops using GIS and a modified land ecological suitability evaluation model. Pedosphere, 22, 122, 2012.

6. XIANG Y.Y., MENG J.J. Research into ecological suitability zoning and expansion patterns in agricultural oases based on the landscape process: a case study in the middle reaches of the Heihe River. Environmental Earth Sciences, 75, 1355, 2016.

7. GUO X., YAN D., FAN J.R., ZHU W.Z., LI M.H. Using GIS and Fuzzy Sets to Evaluate the Olive Tree's Ecological Suitability in Sichuan Province. Computing in Science and Engineering, 12, 20, 2010.

8. LU Z., QIN X.Y., LI Q.F., YU Y., ZANG C.L., HUAI H.J. Quantitative evaluation method and universal tool for crop ecological suitability. Transactions of the Chinese Society of Agricultural Engineering, 28, 195, 2012 [In Chinese].

9. ZHANG D.F., ZHANG Q., GUO J., SUN C.Z., WU J., NIE X., XIE C.X. Research on the global ecological suitability and characteristics of regions with Angelica sinensis based on the MaxEnt model. Acta Ecologica Sinica, 37, 5111, 2017 [In Chinese].

10. LI G.Q., LIU C.C., LIU Y.G., YANG J., ZHANG X.S., GUO K. Advances in theoretical issues of species distribution models. Acta Ecologica Sinica, 33, 4827, 2013 [In Chinese].

11. ZHU G.P., LIU Q., GAO Y.B. Improving ecological niche model transferability to predict the potential distribution of invasive exotic species. Biodiversity Science, 22, 223, 2014 [In Chinese].

12. MA S.M., WEI B., LI X.C., LUO C., SUN F.F. The impacts of climate change on the potential distribution of Haloxylon ammodendron. Chinese Journal of Ecology, 36, 1243, 2017.

13. XU Z.L., PENG H.H., PENG S.Z. The development and evaluation of species distribution models. Acta Ecologica Sinica, 35, 557, 2015 [In Chinese].

14. PHILLIPS S.J., ANDERSON R.P., SCHAPIRE R.E. Maximum entropy modeling of species geographic distributions. Ecological Modelling, 190, 231, 2006.
15. SUN J.S., ZHOU G.S. Inter-decadal variability of winter wheat planting zone in China during 1961 to 2010 simulated by maximum entropy (MaxEnt). Chinese Journal of Agrometeorology, 33, 481, 2012 [In Chinese].

16. KOGO B.K., KUMAR L., KOECH R., KARIYAWASAM C.S. Modelling climate suitability for rainfed maize cultivation in Kenya using a maximum entropy (MaxENT) approach. Agronomy, 9, 727, 2019.

17. FENG L., WANG H., MA X., PENG H., SHAN J. Modeling the current land suitability and future dynamics of global soybean cultivation under climate change scenarios. Field Crops Research, 263, 108069, 2021.

18. DUAN J.Q., ZHOU G.S. Potential distribution of rice in china and its climate characteristics. Acta Ecologica Sinica, 31, 6659, 2011 [In Chinese].

19. CHEN J.H. Approach the cultivation technique of lemon tree with high yield. Tropical Agricultural Science and Technology, 34, 14, 2011 [In Chinese].

20. LI J.X., PENG M.X., YANG E.C., GAO J.Y., ZHOU D.G., YUE J.Q. Key annual management techniques for efficient cultivation of spring flowering lemon in Dehong of Yunnan province. Hunan Agricultural Sciences, 1, 99, 2013 [In Chinese].

21. ZHANG Q., ZHANG D.F., SUN C.Z., XIE C.X. Numerical analysis of climatic characteristics and geographical distribution of medicinal plants - taking sichuan province as an example. Modern Chinese Medicine, 20, 145-, 2018 [In Chinese].

22. LIU L., GUAN L.L., ZHAO H.X., HUANG Y., MOU Q.Y., LIU K., CHEN T.T., WANG X.Y., ZHANG Y., WEI B., HU J. Modeling habitat suitability of Houttuynia cordata Thunb (Ceercao) using MaxEnt under climate change in China. Ecological Informatics, 63, 101324, 2021.

23. WANG R.L., JIANG C.X., HUANG T.T., ZHANG Z., LI Q. A Simulation Study of the Geographical Distribution of Actinidia arguta in China. Polish Journal of Environmental Studies, 29, 1889, 2019.

24. WANG R.L., YANG H., WANG M.T., ZHANG Z., LI Q. Predictions of potential geographical distribution of Diaphorina citri (Kuwayama) in China under climate change scenarios. Scientific Reports, 10, 1, 2020.

25. CHEN H.Y., XIAO T.G., XIONG J.D., ZHU D., CHEN W.B. Eco-climatic environment conditions and its changes of lemon growth in Anyue area. Journal of Chengdu University of Information Technology, 24, 582, 2009 [In Chinese].

26. CHEN L., YAO P. Agroclimatic regionalization of lemon planting in Jialing of Nanchong. Modern Agriculture Research, 1, 74, 2019 [In Chinese].

27. LIN X.Y., HUANG Y., GAO C.Z. Climatic regionalization of lemon in Weiyuan county. Xian Dai Nong Ye Ke Ji, 1, 65, 2019 [In Chinese].

28. ELITH J., GRAHAM C.H., ANDERSON R.P., DUDÍK M., FERRIER S., GUISAN A., HIJMANS R.J., HUETTMANN F., LEATHWICK J.R., LEHMANN A. Novel methods improve prediction of species' distributions from occurrence data. Ecography, 29, 129, 2010.

29. WANG R.L., YANG H., WANG M.T., ZHANG Z., LI Q. Predictions of potential geographical distribution of Diaphorina citri (Kuwayama) in China under climate change scenarios. Sci. Rep., 10, 1, 2020.

30. YANG X.Q., KUSHWAHA S.P.S., SARAN S., XU J.C., ROY P.S. Maxent modeling for predicting the potential distribution of medicinal plant, Justicia adhatoda L. in Lesser Himalayan foothills. Ecological Engineering, 51, 83, 2013. 
31. LEMKE D., HULME P.E., BROWN J.A., TADESSE W. Distribution modelling of Japanese honeysuckle (Lonicera japonica) invasion in the Cumberland Plateau and Mountain Region, USA. Forest Ecology \& Management, 262, 139, 2011.

32. LENG W.F., HE H.S., BU R.C., DAI L.M., HU Y.M., WANG, X.G. Predicting the distributions of suitable habitat for three larch species under climate warming in Northeastern China. Forest Ecology \& Management, 254, 420, 2008.

33. ORTEGA-HUERTA M.A., PETERSON A.T. Modeling ecological niches and predicting geographic distributions: a test of six presence-only methods. Revista Mexicana De Biodiversidad, 79, 205, 2008.

34. REMYA K., RAMACHANDRAN A., JAYAKUMAR S. Predicting the current and future suitable habitat distribution of Myristica dactyloides Gaertn. using MaxEnt model in the Eastern Ghats, India. Ecological Engineering, 82, 184, 2015.

35. ZOU J., TENG F., FU S. The Latest Progress in Socioeconomic Assessment of the Mitigation of Climate Change-Review of the IPCC Fifth Assessment WGIII Report. Progressus Inquisitiones De Mutatione Climatis, 10, 313, 2015 [In Chinese].

36. HE S.T., BAI B.Y., DAN J.H., ZHAO J.Y., GAO Q.Q., JING P.F. Prediction distribution areas of Salvia bowletana Dunn, in China based on Maxent and suitability analysis. Journal of Anhui Agricultural Sciences, 42, 2311, 2014 [In Chinese].

37. GUO F.L., XU G.B., MU H.L., LI Z. Simulation of potential spatiotemporal population dynamics of Bretschneidera sinensis Hemsl. based on MaxEnt model. Plant Science Journal, 38, 185, 2020.

38. WANG L., WEI F.F., CHENG X., ZHAO W.L., JIN L. Study on Suitability Zoning of Astragalus membranaceus var. mongholicus in Dingxi City Based on MaxEnt and ArcGIS. China Pharmacy, 31, 321, 2020 [In Chinese].

39. LIN Z.Y., CHEN Q., DENG L.J., LI X., HE P., XIONG Y. Response of suitable distribution of citrus in Sichuan Province to climate change. Chinese Journal of EcoAgriculture, 27, 845, 2019 [In Chinese].

40. ROMERO-ROMERO J.L., INOSTROZABLANCHETEAU C., REYES-DÍAZ M., MATTE J.P., ARCE-JOHNSON P. Increased drought and salinity tolerance in citrus aurantifolia (Mexican Lemon) plants wverexpressing arabidopsis CBF3 gene. Journal of Soil Science and Plant Nutrition, 20, 244, 2019.

41. KOVÁCS G., NAGY G., ZÁMBORI-NÉMETH É. Journal of Plant Protection Research. Journal of Plant Diseases and Protection, 60, 51, 2020.

42. LIU H.M., LONG C.R., LI J.X., FU X.M., ZHOU D.G., GAO J.Y., DONG M.C., YUE J.Q. A study on photosynthetic characteristics and fruiting performance of three lemon varieties in dry-hot valley regions in Yunnan province. Journal of Fruit Science, 34, 59, 2017.

43. TU X.L., YANG S.T., LI Y.B., ZHANG L., LV X.L. Analysis of aromatic components from the peels of eight lemon varieties by GC-MS. Plant Sclence Journal, 34, 630, 2016.

44. CHEN Y., ZHANG D., PAN H.L., SUN J.H., PAN D.M., YU W.Q. Antioxidant capacity of different varieties of citrus peels. Chinese Journal of Tropical Crops, 40, 1633, 2019.

45. CHEN H.M., WANG X.F., ZHOU Y., ZHOU C.Y., GUO J., LI Z.A. Biological characterization and RT-PCR detection of a new disease of Eureka lemon. Acta Phytophylacica Sinica, 42, 557, 2015.

46. TEKINER N., TOZLU E., GUARNACCIA V. First report of Diaporthe foeniculina causing fruit rot of lemon in Turkey. Journal of Plant Pathology, 102, 277, 2020.

47. SONG S.Y., YU L.Z., YANG J., QI L.J., XU F. Morphological and molecular identification of Tylenchulus semipenetrans in lemon tree seedlings. Plant Quarantine, 33, 43, 2019.

48. PETITPIERRE B., KUFFER C., BROENNIMANN O., RANDIN C. Climatic niche shifts are rare among terrestrial plant invaders. Science, 335, 1344, 2012.

49. ELITH J., GRAHAM C.H., ANDERSON R.P., DUDÍK M., FERRIER S., GUISAN A., HIJMAN R.J., HUETTMANN F., LEATHWICK J.R., LEHMANN A. Novel methods improve prediction of species' distributions from occurrence data. Ecography, 29, 129, 2010.

50. PETERSON A.T. Predicting the potential distribution of alien pests in the UK under global climate change: Diabrotica virgifera virgifera. Condor, 103, 599, 2001.

51. WARREN D.L., SEIFERT S.N. Ecological niche modeling in Maxent: the importance of model complexity and the performance of model selection criteria. Ecological Applications, 21, 335, 2011.

52. YING L.X., LIU Y., CHEN S.T., SHEN Z.H. Simulation of the potential range of Pistacia weinmannifolia in Southwest China with climate change based on the maximum-entropy (Maxent) model. Biodiversity Science, 24, 453, 2016 [In Chinese].

53. WANG R.L., YANG H., LUO W., WANG M.T., LI Q. Predicting the potential distribution of the Asian citrus psyllid, Diaphorina citri (Kuwayama), in China using the MaxEnt model. Peer J, 7, e7323, 2019.

54. GUO J., LIU X.P., ZHANG Q., ZHANG D.F., XIE C.X., LIU X. Prediction for the potential distribution area of Codonopsis pilosula at global scale based on Maxent model. Chinese Journal of Applied Ecology, 28, 992, 2017 [In Chinese].

55. ZHANG H.T., LUO D., MU X.D., XU M., WEI H., LUO J.R., ZHANG J.E., HU Y.C. Predicting the potential suitable distribution area of the apple snail Pomacea canaliculata in China based on multiple ecological niche models. Chinese Journal of Applied Ecology, 27, 1277, 2016 [In Chinese]

56. WANG R.L., LI Q., HE S.S., LIU Y. Potential distribution of Actinidia chinensis in China and its predicted response to climate change. Chinese Journal of Eco-Agriculture, 26, 27, 2018 [In Chinese].

57. FAN X., PAN J.W., HE S.T. Prediction of the potential distribution of Rosa roxburghii under the background of climate change based on MaxEnt model. Acta Botanica Boreali-Occidentalia Sinica, 41, 159, 2021 [In Chinese].

58. LI Y., YANG X.G., ZHANG H.L., CHEN F. The possible effects of global warming on cropping systems in china VII. The possible effects of climate warming on geographical shift in northern limit of citrus planting areas and the risk analysis of freezing injury in China. Scientia Agricultura Sinica, 44, 28765, 2011 [In Chinese].

59. DJAMAN K., KOUDAHE K., DARAPUNENI M., IRMAK S. Chilling and Heat Accumulation of Fruit and Nut Trees and Flower Bud Vulnerability to Early Spring Low Temperatures in New Mexico: Meteorological Approach. Sustainability, 13, 2524, 2021.

60. BONDÉ L., OUÉDRAOGO O., TRAORÉ S., THIOMBIANO A., BOUSSIM J.I. Impact of 
environmental conditions on fruit production patterns of shea tree (Vitellaria paradoxa C.F.Gaertn) in West Africa. African Journal of Ecology, 57, 353, 2019.

61. GARZÓN M.B., ALÍA R., ROBSON T.M., ZAVALA M.A. Intra-specific variability and plasticity influence potential tree species distributions under climate change. Global Ecology and Biogeography, 20, 766, 2011.
62. STAHL U., REU B., WIRTH C. Predicting species' range limits from functional traits for the tree flora of North America. Proceedings of the National Academy of Sciences of the United States of America, 111, 13739, 2014.

\section{Supplementary Material}
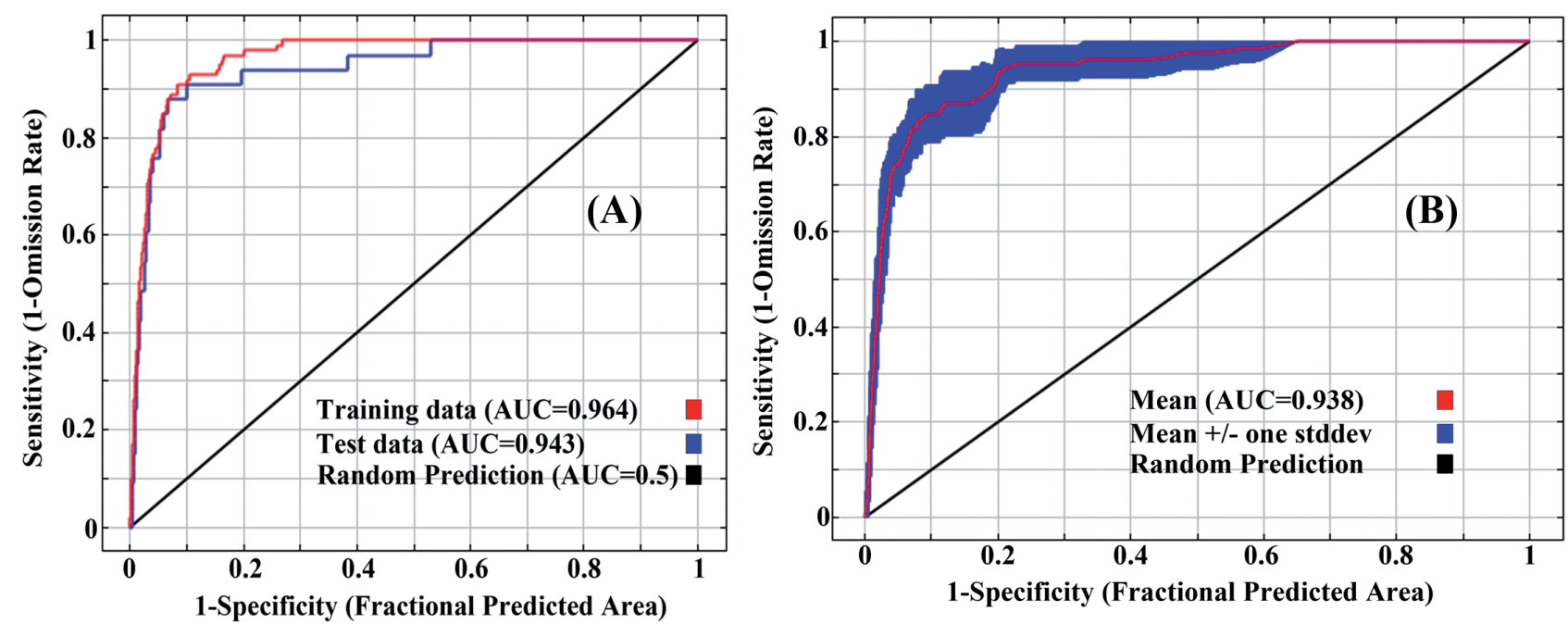

Fig. S1. ROC curves for the MaxEnt model based on potential climatic factors a) and dominant climatic factors b). 